\title{
Analysis of Wireless Power Transfer on the Inductive Coupling Resonant
}

\author{
Cik Ku Haroswati Che Ku Yahaya ${ }^{1}$, Syed Farid Syed Adnan², Murizah Kassim³ ${ }^{3}$ Ruhani Ab Rahman ${ }^{4}$, \\ Mohamad Fazrul bin Rusdi ${ }^{5}$ \\ 1,2,3,4,5 Faculty of Electrical Engineering, Universiti Teknologi MARA, 40450 UiTM Shah Alam, Malaysia \\ ${ }^{1}$ Pusat Asasi UiTM, Universiti Teknologi MARA, Kampus Dengkil, 43800 Dengkil, Selangor, Malaysia
}

\section{Article Info}

Article history:

Received May 4, 2018

Revised Jul 5, 2018

Accepted Jul 19, 2018

\section{Keywords:}

Electrical load

Inductive coupling

Inductor coils

Magnetic induction

Wireless power transfer

\begin{abstract}
Wireless power transfer through inductive coupling is proposed in this paper. Based on the concept of Tesla, the circuit was designed using two parallel inductors that are mutually coupled. The designed was split into two which are transmitter part and receiver part. The circuit was simulated using proteus simulation software. The results had shown that the changes in a number of turn of the inductor coils and distance of the two resonators affecting the efficiency of the power transfer. The wireless power transfer can be described as the transmission of electrical energy from the power source to the electrical load without any current-carrying wire connecting them. Wireless power transfer is deemed to be very useful in some circumstances where connecting wires are inconvenient. Wireless power transfer problems are different from wireless telecommunications such as radio. Commonly, wireless power transfers are conducted using an inductive coupling and followed by magnetic induction characteristics. In this project, we use magnetic induction using copper wire with a different diameter. By using these different diameters of wires, we are going to see the power transfer performance of each wire. It is possible to achieve wireless power transfer up to 30 centimeters between the transmitter and the receiver with a higher number of coil's turn. As concern as it may seem, the wireless power transfer field would be in high demand for electric power to be supplied in the future.
\end{abstract}

Copyright $\odot 2018$ Institute of Advanced Engineering and Science. All rights reserved.

\section{Corresponding Author:}

Cik Ku Haroswati Che Ku Yahaya, Faculty of Electrical Engineering, Universiti Teknologi MARA, 40450 UiTM Shah Alam, Malaysia. Email: haroswati@salam.uitm.edu.my

\section{INTRODUCTION}

The world we are living now is a world where technology becomes part of our life. The advancement of new technology grows rapidly each day. It can say that almost every day new technology will emerge to our world. Despite all these technologies, certain problems related to the limited amount of power socket will occur. Too many gadgets functioning at one place will surely limit the use of power socket to power up the gadgets. This will also create a mess when the wires become scattered and disorganized. Wireless Power Transfer (WPT) is among the technology that has started its growing phase. Over the past era, this technology has evolved and comes in handy as power can be transferred wirelessly. Wireless transmission can replace the current-carrying wire which is the main interconnecting medium between power source and load. Wireless power transfer is the transmission of electrical energy from a power source to an electrical load without any wires or to be precise, conductors attached between them.

Wireless power transfer (WPT) is an important topic that been discussed among researchers and engineers nowadays. Although WPT has been known for more than a century, the development of the WPT 
industry just started its rapid growth in early 2000's. The number of publications on wireless power has increased by at least $1200 \%$ in the last 10 years [1]. In the 1890 's, a wireless power transfer (WPT) system was introduced and demonstrated by Nikola Tesla. In his demonstration, he used a resonant transformer call Tesla coils [2]. Back in the time of Tesla, the development of wireless power transfer could not go any further as there is a certain restriction such as funding and the technology itself. Thus the development of WPT technology was left as it was without any thorough research [3].

Currently, engineers are trying to figure out how to increase the efficiency of power that is being transmitted wirelessly and also methods to make human beings and the environment safer as well as methods that is cheaper and hence can be commercialized. Though still in the early stages, there are several electronic companies that have begun to roll out devices that can wirelessly transmit power. The idea of how to make wireless power transmission (WPT) is taken from the principle of electromagnetic induction. Electromagnetic induction works on the concept of a primary coil generating a certain amount of magnetic field and a secondary coil being within that field so a current is induced within its coils. This causes the relatively short range due to the amount of power required to produce an electromagnetic field.

In 2007, a group of researchers from MIT did a research on WPT and managed to power a light bulb of $60 \mathrm{~W}$ over distances exceeding 2 meters with an efficiency of around 40\% [4]. This was done by using a pair of resonators that magnetically coupled. Those pair of the resonator is called a transmitter and a receiver, forming a resonant pair or in another word magnetic resonance coupling technology. Since then, many researchers started doing their research on wireless power transfer.

\subsection{Current Technology of Wireless Power Transfer}

a) Microwave power transmis

Microwave transmission was introduced by the pioneer in wireless power transfer, William C Brown. He explained how a power can be transmitted through free space by using microwaves. The block diagram as shown in Figure 1 [5].

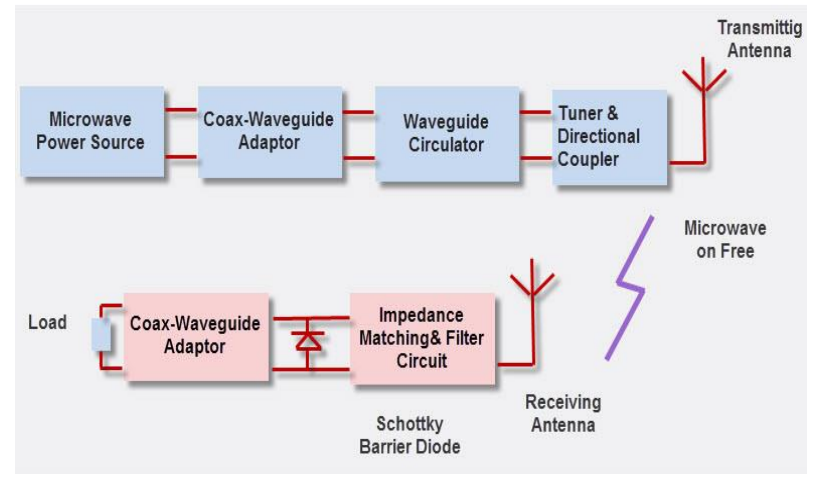

Figure 1. Block Diagram of power transmission using microwave [10]

As the block diagram shows, from the generation side, the microwave power source generates power. Meanwhile, the output power is controlled by electronic control circuits the waveguide circulator protects the microwave source from reflected back through the coaxwaveguide adaptor. The tuner will match the impedance between the transmitting antenna and the microwave source. The transmitting antenna radiates the power through free space towards the receiving antenna. Once the receiving antenna received power, it will convert it into DC power.

b) Solar Power Satellite (SPS)

The idea of solar power satellite was proposed by Peter Glaser in 1968's. Solar power satellite(SPS) also known as Space Power Station, Satellite Power System, Space Power System, Solar Power Station, Space Solar Power Station use the microwave power transmission to transmit to transmit power to Earth stations [6]. During the Oil Crises of 1970's, the idea of solar satellite gained attention for engineers but after the prices of oil stabilized, the momentum dropped drastically. The restriction towards continuing the project is the launching cost of the satellite is costly and lesser government's support. But then again, the US Department of Energy Research running a programme about SPS from 1978 until 1981. 


\subsection{History of Wireless Power Transfer}

The history of wireless power transfer started in 1820, where André-Marie Ampère, a physicist, and mathematician from French developed Ampere's law. During his research, he discovered that electric current produces a magnetic field [7]. Then in the year of 1831, an English scientist, Michael Faraday developed Faraday's law. Faraday's Law outlining the principle of electromagnetic force induced in a conductor through magnetic flux [8]. But the real people who actually created the ideas of wireless power transfer were Heinrich Hertz and Nikola Tesla around the year 1890's [8]. In 1899, Nikola Tesla builts a huge coil tower to conduct his experiments in Colorado Springs, Colorado. The tower' height was measured around $60 \mathrm{~m}$ had a copper ball positioned at the top. And there also was an iron root system that goes underground for more than 90 meters, as shown in Figure 2 [9].

Tesla got his funds from Colonel John Jacob Astor, owner of the Waldorf-Astoria Hotel in New York City, for about $\$ 30,000$. In his vision, he wants his invention to change the world. He was widely regarded as America's greatest electrical engineer in 1900's. Another Tesla's inventions including Tesla's coils, fluorescent lamps and radio transmitter [8].

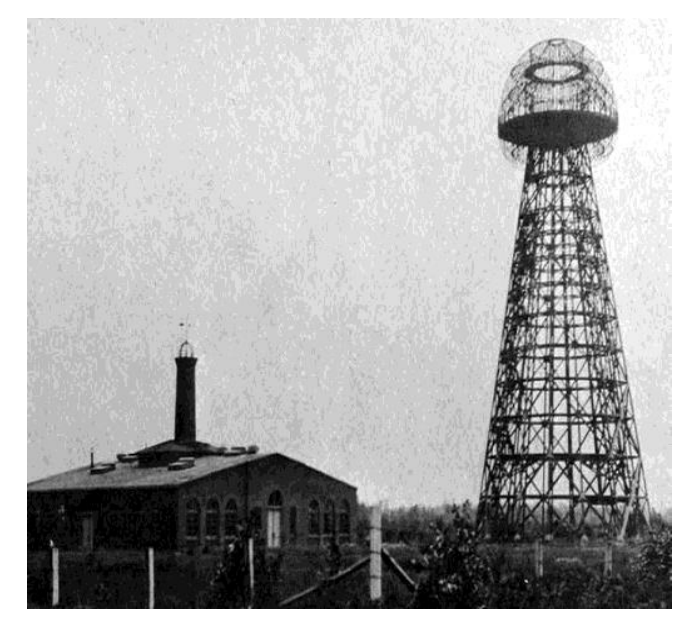

Figure 2. Tesla's tower on Long Island, New York [9]

The work of Tesla then been continued by William C. Brown. He contributed much to the modern development of microwave power transmission which dominates research and development of wireless transmission today. He invented the rectenna that can convert microwaves to DC currents directly in the 1960s. He then demonstrated his research in 1964 by powering a helicopter through microwaves [3]. Again in 2007, Soljacic's team from MIT had done the specific tuning of transmitting unit with receiving the device. The main aim 'coupling resonance' system, was that the electric energy that was not getting used up by the receiver did not get radiated in the environment around, but it did remain in the vicinity of transmitter [14].

MIT team experimentally showed the wireless power transfer, potentially useful for charging of laptops, cell phones without any wires or cords. Imagine a future in which wireless power transfer is feasible where for example; cell phones, laptop or any other portable electronic devices are capable of getting charged up without ever being plugged into the socket. With these experiments, we get ideas of creating one such source providing us with wireless power transmission and enabling to use electricity without the involvement of not much safe also a bit inefficient wire work saving on energy as well [15].

\subsection{Mutual Inductance and Ampere's Law}

When two devices are mutually coupled using a magnetically coupled method, any changes in current in the first coil will induce a voltage in the second wire through electromagnetic induction. This phenomenon is known as mutual inductance. Example of this phenomenon is transformer, as shown in Figure 3 [13]. There is two type of transformer which is step up and step down transformer. Factors for mutual inductance depends on a number of turns. Basically, the larger the number of turns, the larger the mutual inductance. Besides, if both coils have a larger cross-sectional area, the mutual inductance will become larger as well. Lastly, if the distance between the two coils is further, the smaller the value of inductance. This is due to the magnetic flux that goes from primary coil to the secondary coil. 


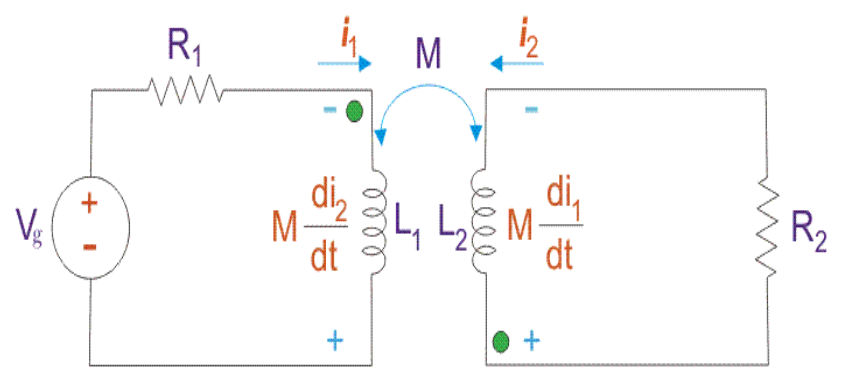

Figure 3. Mutual inductance circuit diagram

$$
\mathrm{M}=\frac{\mu_{\mathrm{o}} \mu_{\mathrm{r}} \mathrm{N}_{1} \mathrm{~N}_{2} \mathrm{~A}}{\ell}
$$

Where:

$\mu_{o}$ is the permeability of free space $\left(4 \cdot \pi \cdot 10^{-7}\right)$

$\mu_{\mathrm{r}}$ is the relative permeability of the soft iron core

$\mathrm{N}$ is in the number of coil turns

$\mathrm{A}$ is in the cross-sectional area in $\mathrm{m}^{2}$

1 is the length of the coil in meters

$$
\begin{aligned}
& \mathrm{M}_{12}=\frac{\mathrm{N}_{2} \Phi_{12}}{\mathrm{I}_{1}} \\
& \mathrm{~L}_{1}=\frac{\mu_{\mathrm{o}} \mu_{\mathrm{r}} \mathrm{N}_{1}^{2} \mathrm{~A}}{\ell} \text { and } \mathrm{L}_{2}=\frac{\mu_{\mathrm{o}} \mu_{\mathrm{r}} \mathrm{N}_{2}^{2} \mathrm{~A}}{\ell} \\
& \mathrm{M}^{2}=\mathrm{L}_{1} \mathrm{~L}_{2} \\
& \mathrm{M}=\sqrt{\mathrm{L}_{1} \mathrm{~L}_{2}} \mathrm{H}
\end{aligned}
$$

Ampere's Law states that whenever there is a motion of charge, Q or current, I there should be a circulation of a magnetic field associated with it. The strength of magnetic field is directly proportional to the amount of current that passes through a conductor.

$$
B=\frac{\mu_{0} I}{2 \pi r}
$$

Where,

$\mathrm{B}=$ Magnetic field in Tesla,

$\mathrm{T}=$ Permeability of free space, $(1.26 \mathrm{x})$

$\mathrm{I}=$ Current in the inductor

$\mathrm{r}=$ Radius of the inductor

\section{RESEARCH METHOD}

To design any project research, the project requires a considerable amount of attention especially in term of the research method and the data analysis that will be used. There are three different characteristics of research paradigms, they are known as qualitative research, quantitative research and mixed research. Quantitative research relies primarily on the collection of qualitative data where the form of data collected by having an observation that can search for patterns of having data analysis. This can conclude a result from viewpoints, particular findings or present multiple perspectives. A collection of quantitative data that is deductive where the researcher tests hypotheses and theory with data and is predictable is a method of

Analysis of Wireless Power Transfer on the Inductive Coupling... (Cik Ku Haroswati Che Ku Yahaya) 
quantitative research approach. To collect quantitative data, based on precise measurement using structured data collection such as behavioral responses is its form of data collected that can identify statistical relationships to obtain generalizable findings. Another research that involves both qualitative and quantitative is a mixed research characteristic [11]. completed.

Figure 4 shows the flowchart of this project. All steps stated in the flowchart has been followed and

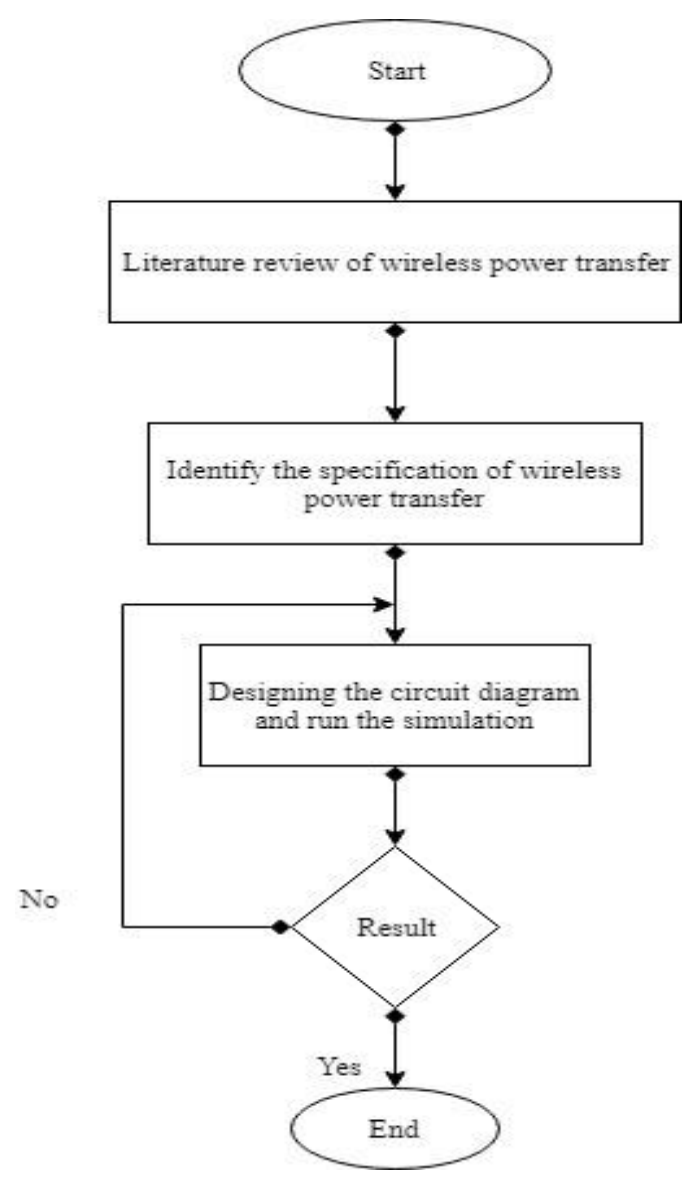

Figure 4. Flowchart of wireless power transfer

\subsection{Resnaont inductive coupling}

Resonant inductive coupling occurs when there is a transmitting of power between two coils that have the same characteristic to resonate at the same frequency. Resonance occurs when the self-resonant frequency of coils equal to the frequency of power supply. Then both circuits of coils will be equivalent. Both circuits will likely to have high frequency and minimum impedance. To see how mutual induction works, the transformer is the closest example of mutual induction, where there is no physical contact between the primary and the secondary coils. The energy transferring takes place due to electromagnetic coupling between the two coils [12].

\subsection{Electromagnetic transmission}

To transfer power without any wire, the electromagnetic transmission can also be used. The electricity is converted into light, such as a laser beam, and then this laser beam will be fired at a receiving target, such as a solar cell on a small aircraft. The laser beam can be beamed to a single target. This is typically known as "power beaming".

\subsection{Circuit diagram and PCB layout}

Figure 5 to Figure 8 show the circuit diagram and PCB layout 


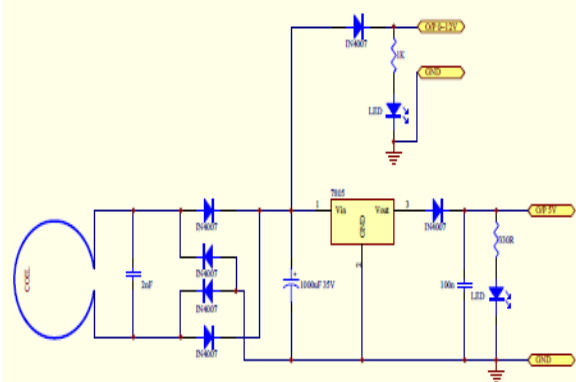

Figure 5. Circuit design for Receiver for Wireless power transfer

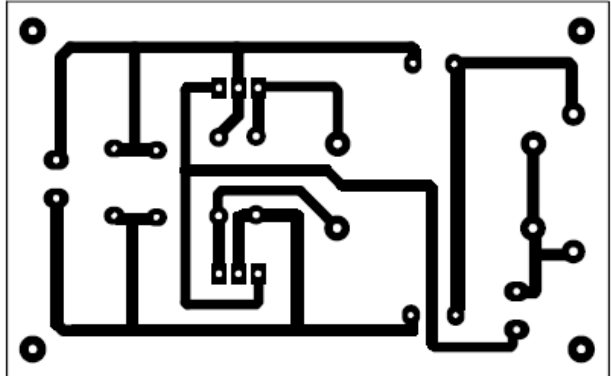

Figure 7. PCB layout for the transmitter

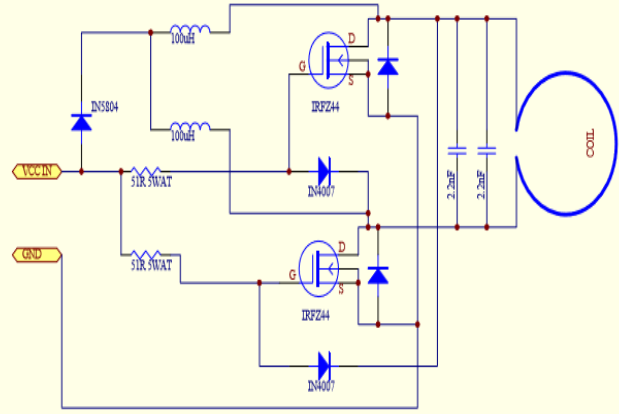

Figure 6. Circuit design for Transmitter for Wireless power transfer

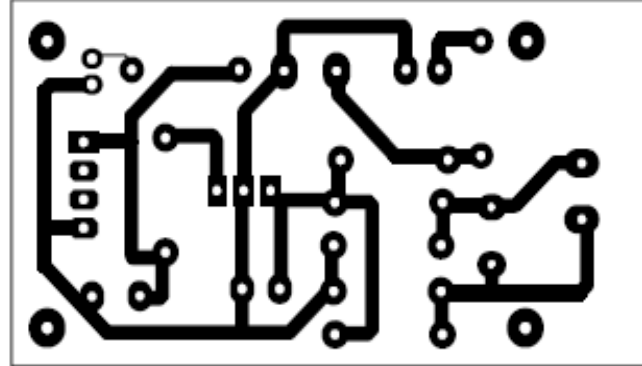

Figure 8. PCB layout for the recever

\section{RESULTS AND ANALYSIS}

Efficiency for the coil with a thickness of $0.61 \mathrm{~mm}$ and $0.73 \mathrm{~mm}$ is calculated by measuring the output parameters of the circuit. These parameters include output voltage, output current, and output power. By varying the distance from $1 \mathrm{~cm}$ until $4 \mathrm{~cm}$ between the transmitter and receiver, the result in Table 1 and 2 shows that there are significant changes in the output power as we increase the distance between transmitter and receiver.

Table 1. Efficiency values for the coil with $0.73 \mathrm{~mm}$ diameter

\begin{tabular}{|l|l|l|l|l|l|l|l|l|}
\hline $\begin{array}{c}\text { Distance, } \\
(\mathrm{cm})\end{array}$ & $\begin{array}{c}\text { Input } \\
\text { Voltage, } \\
(\mathrm{V})\end{array}$ & $\begin{array}{l}\text { Output } \\
\text { Voltage, } \\
(\mathrm{V})\end{array}$ & $\begin{array}{l}\text { Input } \\
\text { Current, } \\
(\mathrm{mA})\end{array}$ & $\begin{array}{l}\text { Output } \\
\text { Current, } \\
(\mathrm{mA})\end{array}$ & $\begin{array}{l}\text { Power } \\
\text { Input, } \\
(\mathrm{W}) \\
\mathrm{P}=\mathrm{IV}\end{array}$ & $\begin{array}{l}\text { Power } \\
\text { Output, } \\
(\mathrm{w})\end{array}$ & $\begin{array}{l}\text { Efficiency } \\
(\eta)\end{array}$ & $\begin{array}{l}\text { Gain, } \\
(\mathrm{dB}) 20 \\
\text { log } \\
(\mathrm{Vo} / \mathrm{Vi})\end{array}$ \\
\hline 1 & 12 & 4.93 & 0.366 & 0.104 & 4.392 & 0.5127 & 11.67 & -7.7266 \\
\hline 2 & 12 & 4.25 & 0.366 & 0.082 & 4.392 & 0.3485 & 7.93 & -9.0158 \\
\hline 3 & 12 & 3.24 & 0.366 & 0.051 & 4.392 & 0.1652 & 3.76 & -11.3727 \\
\hline 4 & 12 & 0.81 & 0.366 & 0.024 & 4.392 & 0.0194 & 0.44 & -23.4139 \\
\hline
\end{tabular}

Table 2. Efficiency values for the coil with $0.61 \mathrm{~mm}$ diameter

\begin{tabular}{|l|l|l|l|l|l|l|l|l|}
\hline $\begin{array}{c}\text { Distance, } \\
(\mathrm{cm})\end{array}$ & $\begin{array}{c}\text { Input } \\
\text { Voltage, } \\
(\mathrm{V})\end{array}$ & $\begin{array}{l}\text { Output } \\
\text { Voltage, } \\
(\mathrm{V})\end{array}$ & $\begin{array}{l}\text { Input } \\
\text { Current, } \\
(\mathrm{A})\end{array}$ & $\begin{array}{l}\text { Output } \\
\text { Current, } \\
(\mathrm{A})\end{array}$ & $\begin{array}{l}\text { Power } \\
\text { Input, } \\
(\mathrm{W}) \\
\mathrm{P}=\mathrm{IV}\end{array}$ & $\begin{array}{l}\text { Power } \\
\text { Output, } \\
(\mathrm{w})\end{array}$ & $\begin{array}{l}\text { Efficiency } \\
(\eta)\end{array}$ & $\begin{array}{l}\text { Gain, } \\
(\mathrm{dB}) \text { 20 } \\
\text { log } \\
(\mathrm{V} / \mathrm{V} \text { ) })\end{array}$ \\
\hline 1 & 12 & 10.41 & 0.817 & 0.5371 & 9.804 & 5.5907 & 57.02 & -1.2346 \\
\hline 2 & 12 & 8.64 & 0.817 & 0.3184 & 9.804 & 2.7471 & 28.05 & -2.8533 \\
\hline 3 & 12 & 5.78 & 0.817 & 0.1465 & 9.804 & 0.8092 & 8.63 & -6.3451 \\
\hline 4 & 12 & 1.96 & 0.817 & 0.0302 & 9.804 & 0.0588 & 0.60 & -15.7385 \\
\hline
\end{tabular}




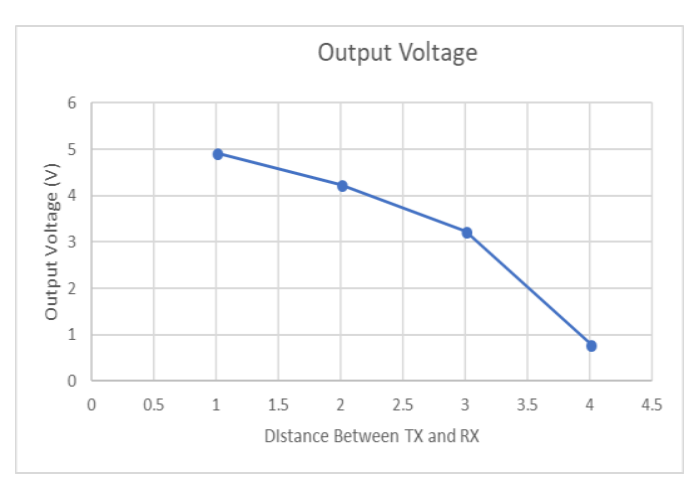

Figure 9. Graph of Output Voltage versus Distance for copper with $0.73 \mathrm{~mm}$ diameter

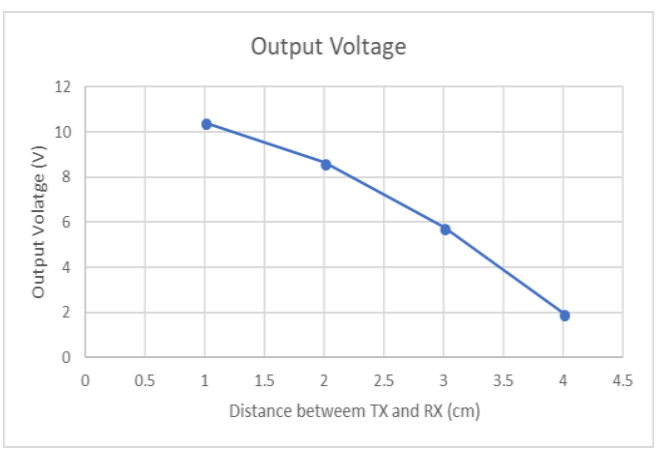

Figure 10. Graph of Output Voltage versus Distance for copper with $0.61 \mathrm{~mm}$ diameter

As the result had shown, for the copper with the diameter of $0.73 \mathrm{~mm}$, when the distance between the transmitter and the receiver increased from $1 \mathrm{~cm}$ to $4 \mathrm{~cm}$, the voltage decreased from $4.93 \mathrm{~V}$ to $0.81 \mathrm{~V}$. While for the copper with the diameter of $0.61 \mathrm{~mm}$, the voltage decreased from $10.41 \mathrm{~V}$ to $1.96 \mathrm{~V}$.

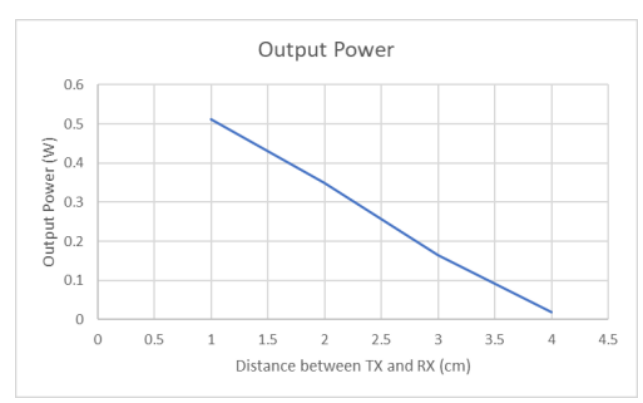

Figure 11. Graph of Output Power versus Distance for copper with $0.73 \mathrm{~mm}$ diamet

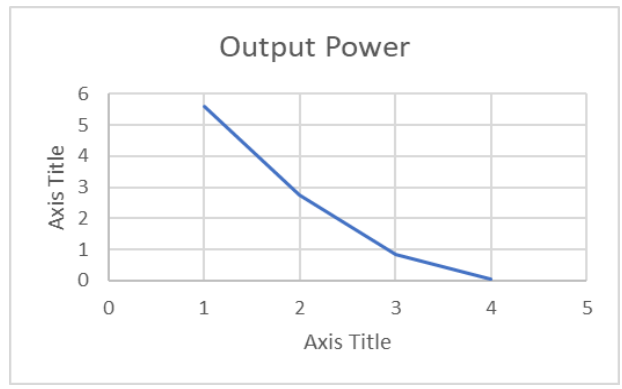

Figure 12. Graph of Output Power versus Distance for copper with $0.61 \mathrm{~mm}$ diameter

The output power decreased as the distance increased. These happen due to the increased output voltage. Voltage and power are related by the formula (8). The output power for copper with the diameter of $0.71 \mathrm{~mm}$ at $1 \mathrm{~cm}$ distance is $0.5127 \mathrm{~W}$ and at the distance of $4 \mathrm{~cm}$, the output power is 0.0194 . While for the copper with the diameter of $0.61 \mathrm{~mm}$, the output power at the $1 \mathrm{~cm}$ distance is $5.5907 \mathrm{~W}$ and decreased to $0.0588 \mathrm{~W}$ at the $4 \mathrm{~cm}$ distance. Thus we can conclude that the distance and the diameter of the copper transmitter and receiver have bigger impacts on the power that is transmitted.

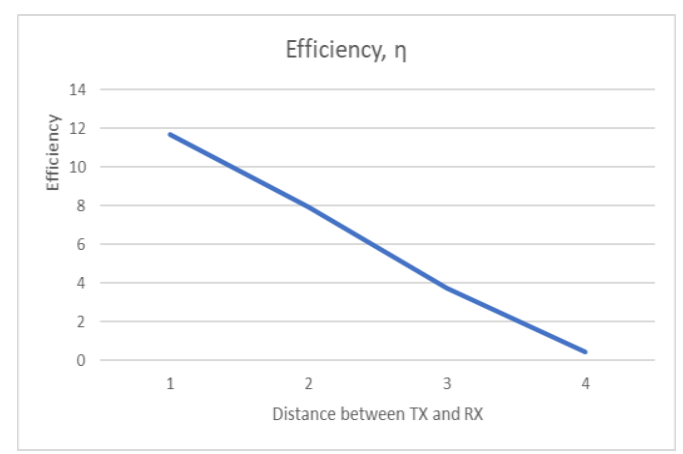

Figure 13. Graph of Efficiency versus Distance fort copper with 0.73 diameter

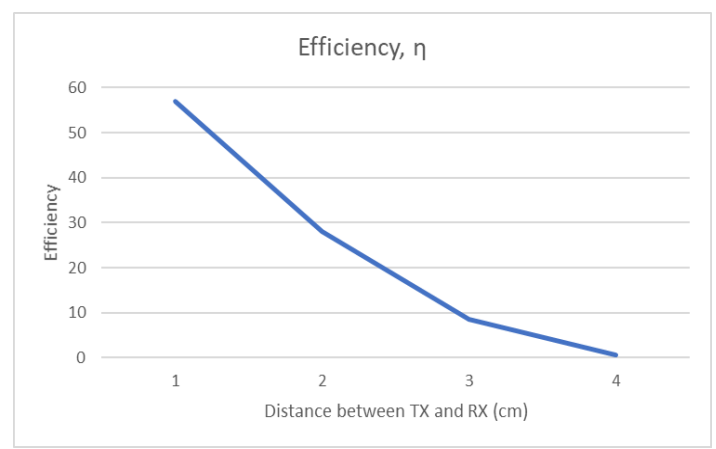

Figure 14. Graph of Efficiency versus Distance fort copper with $0.61 \mathrm{~mm}$ diameter 
The efficiency for the power transfer for copper with the diameter of $0.73 \mathrm{~mm}$ as shown on the graph is decreasing as the distance increases. The efficiency dropped from $11.67 \%$ at $1 \mathrm{~cm}$ distance to $0.44 \%$ at 4 $\mathrm{cm}$ distance. Meanwhile, for copper with the diameter of $0.61 \mathrm{~mm}$, the efficiency dropped from $57.02 \%$ to $0.60 \%$. This happens due to the amount of the magnetic flux that goes towards the receiver from the transmitter. Further the distance, the lesser the flux.

\section{CONCLUSION}

As the conclusion of the project, this project has successfully conducted. The objective of analyzing the wireless power transfer was achieved. The results that are recorded had shown the distance between the coils affect the efficiency of the power transfer. The further the distance, the lower the efficiency of the power that is transmitted from the source or transmitter to the receiver or load. Another result that was discovered in this project is the thicker the diameter of the copper, the higher the efficiency of the power transfer

The performance of wireless power transfer can be further explored to increase the efficiency of the power transferred. This can be done by improving the Q-factor. The transmission distance of wireless power transfer should also be a concern as WPT system supposedly should be able to harness the power or energy for long distances. Lastly, there should be a development of security of energy or power that is being transferred. As the power or energy is being transferred by electromagnetic field through open surrounding, it is possible that the energy or power transferred can interfere with other receivers. Thus, the study on the security can be a really profitable research in the future.

\section{REFERENCES}

[1] V. Khayrudinov, "Wireless Power Transfer System," no. March 2015.

[2] M. A. Hassan, A. Elzawawi, F. Field, and N. Field, "Wireless Power Transfer through Inductive Coupling," pp. $115-118,2015$.

[3] T. S. H. and R. M. H. Sagolsem Kripachariya Singh, "Wireless Transmission of Electrical Power Overview of Recent Research \& Development," Int. J. Comput. Electr. Eng., vol. 4, no. 2, pp. 207-211, 2012.

[4] D. M. S. R. YIN QUAN TEO, "Wireless Power Transmission in the SmartHome," vol. 2010.

[5] D. Kajaree and R. Behera, "A Survey on Web Crawler Approaches," Int. J. Innov. Res. Comput. Commun. Eng., vol. 5, no. 2, pp. 1302-1309, 2017

[6] M. S. G. Satavekar, "Solar Power Satellites and Microwave Wireless Power Transmission Technology," vol. 4, no. 2, pp. 193-200, 2014

[7] A. A. Atayero, O. Ajijola, S. I. Popoola, and V. O. Matthews, "Development of a wireless power transfer system using a resonant inductive coupling," Lect. Notes Eng. Comput. Sci., vol. 2225, 2016.

[8] S. Liao, P. Dourmashkin, and J. W. Belcher, "Chapter 11 Inductance and Magnetic Energy," Phys. 8.02 Electric. Magn., pp. 1-53, 2004.

[9] A. Bomber, "Wireless Power Transmission: An Obscure History, Possibly a Bright Future," 2006.

[10] R. Jain, "Cut the Cord: Wireless Power Transfer, its Applications, and its limits Abstract: Keywords: Table of Contents," pp. 1-11, 2014.

[11] A. Hanelt, I. Nastjuk, H. Krüp, M. Eisel, and C. Ebermann, "Disruption on the Way? The Role of Mobile Applications for Electric Vehicle Diffusion," WI Proceedings but. Intell. Anal. From Big Data To Big Impact, pp. 1023-1037, 2015.

[12] M. Augustine and M. Duke, "Wireless Power Transmission," vol. 5, no. 10, pp. 125-129, 2014.

[13] A. Kumar, R. A. Siddiqui, S. Pahuja, M. Sukalikar, and V. Gambhir, "Wireless Power Transmission Using Mutual Inductance," vol. 6, no. 6, pp. 6301-6304, 2016.

[14] Prof. Burali Y. N, 2, Prof. Patil C.B., "Wireless Electricity Transmission Based On Electromagnetic and Resonance Magnetic Coupling” International Journal Of Computational Engineering Research (ijceronline.com) Vol. 2 Issue. 7, pp. 48-51, Nov. 2012.

[15] A. Kurs et al., "Wireless Power Transfer via Strongly Coupled Magnetic Resonances," vol. 83, 2007. 